\title{
A CONSTRUÇÃO DA PERSONAGEM TITA A PARTIR DE SUA RELAÇÃO COM A COZINHA EM COMO AGUA PARA CHOCOLATE (1989), DE LAURA ESQUIVEL
}

\section{JAQUELINE DE OLIVEIRA BRANDÃO \\ LURDES MICAELLY NERIS FERREIRA}

RESUM O: O presente artigo tem como finalidade analisar a construção da personagem feminina Tita do romance Como agua para chocolate (1989), de Laura Esquivel, através do ambiente no qual está inserida desde seu nascimento: a cozinha. A protagonista é a filha mais nova de três irmãs, sua Mamãe Elena é uma mulher extremamente rígida, que após a perda de seu marido, assume o controle do rancho e da educação das filhas. Na condição de caçula, Tita é obrigada a seguir uma tradição familiar que lhe proíbe de se casar para cuidar da mãe. Diante dessa circunstância marcada pela submissão, Tita inicia uma trajetória de luta, impulsionada pela vontade de romper não somente com a tradição castradora, mas também com os valores do patriarcado que marginalizam e silenciam a voz feminina. Desse modo, a cozinha - espaço de confinamento e submissão da mulher - propicia um papel de extrema importância na transformação da protagonista.

PALAVRAS-CHAVE: Literatura hispano-americana; personagem feminina; cozinha.

\section{INTRODUÇÃO}

No âmbito específico da literatura hispano-americana, encontramos poucas menções a obras de autoria feminina. A primeira voz feminina da literatura hispânica foi a escritora mexicana Sor Juana Inés de la Cruz (Juana de Asbaje y Ramírez de Santillana), que surgiu durante o período barroco, no século XVII, 
considerada a primeira mulher a romper com o cânone literário, deixando como herança de sua luta uma obra consistente e significativa.

Até a chegada do século XX, a voz da mulher seguiu sendo marginalizada e excluída pela sociedade patriarcal, uma vez que ainda carregava o medo de ser condenada pelo simples fato de escrever. Haja vista que a mulher continuava "fazendo parte do grupo dos excluídos, fora do eixo canônico central, sendo a voz dos sem rosto" (SANTOS, 1999, p. 123).

A partir da década de 1960, o número de obras publicadas por mulheres começa a crescer e na década de 1970 nasce a crítica literária feminina, quando a voz feminina ganha maior visibilidade. Zolin destaca que os estudos desenvolvidos nesse período chegaram à "constatação de que a experiência da mulher como leitora e escritora é diferente da masculina [o que] implicou significativas mudanças no campo intelectual, marcadas pela quebra de paradigmas e pela descoberta de novos horizontes de expectativas" (ZOLIN, 2005, p. 182).

Neste momento, um universo que até então estava sob o jugo do patriarcado começou a emergir para dar seus primeiros passos. Essa nova perspectiva de mundo vem com a intenção de desmascarar os estereótipos construídos sobre os textos de autoria feminina, em geral classificados como "fúteis”, “coisas de mulheres" entre outras expressões inferiorizantes.

Diante dessa perspectiva, a década de 1980 foi o ápice para as obras de autoria feminina, cujas escritoras ganharam maior destaque, feito que as igualou aos já consagrados escritores hispano-americanos. Podemos citar entre elas: Isabel Allende (chilena), Clara Obrigado (argentina), Zoé Valdés (cubana), Carmen Posadas (Uruguaia) e Laura Esquivel (mexicana), cujo principal romance é o foco deste artigo.

\section{A PERSONAGEM FEMININA E A CONSTRUÇÃo de titA EM COMO}

\section{AGUA PARA CHOCOLATE}

O romance Como agua para chocolate, de Laura Esquivel (1989), é constituído por um enredo simples, a narrativa se passa entre os últimos anos do século XIX e as primeiras décadas do século XX, período em que o cenário é marcado por um dos acontecimentos mais importante na história do México: a Revolução 
Mexicana, ocorrida entre os anos de 1910 e 1940. Nesse sentido, a situação enfrentada pela cidade próxima ao rancho da família de La Garza refletia as duras condições vivenciadas pelos mexicanos de forma geral.

Com o nascimento de sua última filha e o óbito do seu marido, Elena vê-se viúva e com três filhas para cuidar; diante de tal circunstância, não encontra outra alternativa a não ser assumir a administração do rancho onde vivem e o comando de sua família. Assim, seguindo os moldes patriarcais já estabelecidos em sua vida, ela passa a comandar o rancho, as filhas e os empregados com "mãos de ferro", sendo extremamente rigorosa para com todos que estão sob seu domínio e não permitindo de forma alguma que alguém venha a se rebelar contra as suas decisões. Elena não permite o diálogo sobre as decisões que toma e, como um general, dita as leis, que geralmente são aceitas sem questionamentos. A criação de suas filhas - Rosaura, Gertrudis e Tita - é pautada por uma lei primordial em vigor naquela casa: a lei do silêncio.

Tita, aos quinze anos, apaixona-se por Pedro Muzquiz e é correspondida. Entretanto, Elena a impede de casar-se, condenando-a a cumprir uma tradição familiar que obrigava a filha caçula a permanecer solteira para cuidar de sua mãe até o último dia de vida. Sendo assim, quando Pedro vem à casa de Elena para pedir Tita em casamento, a mãe oferece ao rapaz a mão de Rosaura, a filha mais velha, que está plenamente preparada para o casamento. Pedro, no intuito de ficar junto à mulher que ama, aceita casar-se com Rosaura.

A partir de então, a narrativa, que já era povoada de personagens femininas, põe em destaque o papel da protagonista; uma vez que, logo após o casamento, a morte da cozinheira Nacha faz com que Tita passe a cozinhar para a família, por isso, a protagonista começa a atuar de forma mais intensa no espaço da cozinha - único lugar que não está sob o controle da mãe. Além das personagens femininas já citadas, as índias Chencha e Nacha, que trabalham no rancho da família de Tita são tidas como pessoas da família, apesar de serem criadas.

Elena é uma personagem construída a partir dos moldes patriarcais, que "deseja manter intacta a estrutura social do colonialismo, e consequentemente, a ideia de que à mulher só resta a alternativa de casar ou, caso isso não aconteça, tomar conta da mãe. Não se admite nenhuma outra possibilidade para a vida feminina” (SANTOS, 1999, p. 126). 
Com base nos pressupostos da crítica literária feminista e na teoria de fases de Showalter (1986), após o levantamento das características das personagens femininas do romance de Esquivel, foi possível observar em qual fase cada filha de Elena se encaixa.

Rosaura é a filha mais velha e nela encontramos uma postura de total submissão e obediência às ordens de Elena, trata-se, portanto, de uma personagem em que podemos ver, como num espelho, os reflexos da personalidade de sua mãe; sendo assim, podemos considerar Rosaura como uma fiel sucessora e reprodutora da postura patriarcalista da mãe, por isso, se encaixa na primeira fase sugerida por Showalter, a fase feminine (feminina), em que se imita e internaliza os valores vigentes.

Gertrudis, a filha do meio, é fruto de uma relação extraconjugal de Elena com o verdadeiro amor de sua vida, José Treviño, com quem "não tinham lhe permitido casar-se [...] por ter nas veias sangue negro" (ESQUIVEL, 2006, p. 113). As características de Gertrudis em nada se assemelham às de sua mãe ou de sua irmã, haja vista que tal personagem é precursora em romper com o rígido sistema familiar ao fugir de casa com um soldado do exército villista e se instalando em um bordel até posteriormente se casar com o soldado com quem havia fugido. Além disso, sua nomeação como generala, diante de uma sociedade que não aceita que a mulher esteja em posição de comando e muito menos expresse sua voz, configura outro rompimento com os padrões patriarcais. De acordo com as fases de Showalter (1986), a postura de Gertrudis se encaixa na segunda fase, feminist (feminista), que corresponde ao protesto feito contra os valores que regem essa sociedade.

Tita, a filha mais nova dentre as três irmãs, é obrigada a seguir a tradição castradora de não se casar para cuidar da mãe até a morte, porém ela não tem a postura de total submissão como Rosaura, nem é tampouco extremista como Gertrudis. A personalidade da protagonista se constrói gradativamente e de modo reflexivo e, com tal postura adquirida, ela conquista seu próprio espaço, rompendo com a tradição familiar, e criando uma nova forma de comunicação, através da comida.

No que se refere ao estudo das fases realizado por Showalter (1986), Tita ocuparia a fase female (fase "fêmea" ou "da mulher"), que tem como característica fundamental a busca de identidade própria e a conquista de seu espaço. Para 
analisá-la mais detida e pormenorizadamente, estabelecemos como recorte sua relação com o espaço da cozinha e a preponderância desse ambiente na formação da personagem.

Ao atentarmos para o título do romance - Como agua para chocolate - temos diversos dados interessantes, conforme sistematiza Sacramento (2009, p. 168), ao dizer que tal expressão "diz muito sobre o universo da novela mexicana. Ela traduz a relação com o fogo, a água e o alimento: a água sob a influência do fogo faz o chocolate entrar em estado de fervura. Portanto, a expressão se aplica em contextos tensos, de ânimos exaltados; ou prenhes de uma atmosfera passional”.

Nesse sentido, o chocolate em estado de "fervura" se assemelha às inúmeras angústias e inquietações que a tradição imposta provoca em Tita. A expressão é mencionada uma única vez ao longo da narrativa, diretamente relacionada à protagonista e conota exatamente essa definição: "Tita literalmente estava 'como água para chocolate'. Sentia-se o mais irritável possível” (ESQUIVEL, 2006, p. 124).

O romance é dividido em doze capítulos, cada um corresponde a um mês do ano e é composto por uma receita culinária perfeitamente realizável, fato que evidencia ainda mais a condição da obra ser recheada de intertextualidade, em específico com elementos originários da cozinha. No entanto, fica latente que o passo a passo para a preparação do prato revela pormenores da vida da protagonista; assim como pondera Santos, ao dizer que "depois do nome da receita e dos ingredientes, nada mais lógico que se encontrasse o modo de fazer. É exatamente no modo de fazer que a autora mistura a confecção da receita com a história da personagem Tita (SANTOS, 1999, p. 124).

A obra original é composta pelo seguinte subtítulo: "novela de entregas mensuales con recetas, amores y remedios, caseros”, que além de ser parte essencial da obra, revela antes mesmo de iniciarmos a sua leitura, a estrutura híbrida, e elementos importantes sobre ela, como o gênero, a forma de publicação, as temáticas, as tipologias; no entanto, o subtítulo foi suprimido na tradução brasileira do romance. Assim como suscita Miranda: 
demais expressões oferecem dados que caracterizam formalmente o romance: "entregas mensuales" (fascículos mensais) remete ao folhetim, publicação fracionada do século XIX; o vocábulo "amores" assinala a presença da temática amorosa, peculiar ao folhetim, e também permite entrever, no contexto geral da obra, uma relação com o diário íntimo, já que esse tipo de relato é comumente associado ao tema do amor. O termo "recetas" alude às receitas culinárias, que figuram de modo notável desde a primeira página do romance, a ponto de este poder ser, num primeiro momento, tomado como um livro de receitas. Por último, a expressão "remedios caseros" refere-se à presença desses elementos na narrativa, os quais remetem ao almanaque - publicação de conteúdos diversos, dentre os quais se encontram orientações sobre remédios (MIRANDA, 2013, p. 87).

O capítulo I, intitulado “Tortas de Natal”, anuncia o nascimento de Tita, que "despencou neste mundo prematuramente sobre a mesa da cozinha" (ESQUIVEL, 2006, p. 4), não foi necessário a famosa palmada na bunda, pois nasceu chorando de tal forma que remetia a "uma torrente impressionante de lágrimas transbordando sobre a mesa e o chão da cozinha" (ESQUIVEL, 2006, p. 5). Portanto, desde o nascimento da protagonista, a cozinha se revela como seu lugar cativo, por isso também é capaz de explicar seu intenso amor pelo espaço e, conforme o romance desenrola, percebemos que tal sentimento evolui gradativamente.

Após o falecimento do pai de Tita, sua mãe não pode manter o aleitamento por ter ficado impressionada e abalada; por isso, Nacha fica encarregada da alimentação da pequena recém-nascida. Nacha é descrita como uma mulher que "nem sequer sabia ler ou escrever, porém sobre cozinha tinha tão profundos conhecimentos como ninguém" (ESQUIVEL, 2006, p. 4). Desse modo, é possível associar o trecho aos ideais e pensamentos da sociedade patriarcal, ao sugerir que as mulheres não tinham a necessidade de estudar já que isto não influenciaria em seus dotes como boas donas de casa.

Sem ser amamentada pela mãe, Tita se muda para a cozinha, crescendo bem alimentada com chás e mingaus preparados por Nacha. Com o passar dos anos, Tita torna-se a única criança dentro da cozinha, uma vez que sua Mãe lhe proibiu brincadeiras nesse espaço.

O primeiro ato de subversão da protagonista se dá com seu nascimento inusitado sobre a mesa da cozinha; já o segundo, é uma tentativa de diálogo com sua 
mãe para compreender a tradição que lhe fora submetida. Vale destacar que o trecho em que se dá tal contestação ocorre durante o ritual da preparação do chouriço, em que todas as mulheres da casa são obrigadas a participar; nessa ocasião, Tita, aflita, avisa a sua mãe que Pedro Muzquiz gostaria de falar com ela, fingindo ignorância do teor da pretendida conversa.

Esse posicionamento de subversão faz com que a mãe encare a atitude da filha como um ato de rebeldia e desobediência ao dizer que "nunca, por gerações e gerações, ninguém em minha família protestou ante este costume e não vai ser uma de minha família que o fará” (ESQUIVEL, 2006, p. 8). Por meio desta fala, fica evidente a característica patriarcal que Elena exerce sobre todo o rancho e, como ela, mesmo sendo mulher, absorveu as ordens de um sistema consolidado há anos.

Indiferente aos sentimentos de Tita, o casamento entre Pedro e Rosaura é marcado. Após a consolidação do matrimonio, Nacha, a melhor amiga, ou ainda a mulher considerada por Tita como mãe, falece, e outra pessoa precisa substituila. No rancho não há outra pessoa mais capacitada para ocupar este cargo do que Tita, portanto a moça é nomeada cozinheira da família.

Tita sente imensamente a ausência de Nacha, mas, por outro lado, o sentimento de estar dentro da cozinha a alegra, pois este é o único ambiente da casa em que se escapa do rigoroso controle de Mamãe Elena. Nesse sentido, a cozinha, comum espaço periférico da casa, destinado apenas às mulheres, tido como um lugar de marginalização e pertencente aos sujeitos excluídos da sociedade, acabava sendo o único lugar em que os representantes do patriarcalismo não podem exercer qualquer tipo de domínio.

Tita assume a cozinha de forma única: "assim como um poeta brinca com as palavras, [...] ela brincava prazerosamente com os ingredientes” (ESQUIVEL, 2006, p. 56), uma vez que possui um vasto conhecimento e os sentidos apurados para tudo o que se refere à cozinha e aos ingredientes. Com o passar do tempo, Tita percebe que seus pratos influenciam de alguma forma àqueles que os desfrutam, como se pudessem exercer controle e criar um código de comunicação através deles.

A protagonista, através da receita “codornas em pétalas de rosa”, descobre um novo código de comunicação para o qual Pedro é o receptor. Além disso, percebe-se também o poder que seus pratos exercem sobre os demais, em específico 
um alimento preparado, que provoca a libertação dos desejos sexuais de sua irmã Gertrudis, encorajando-a a fugir do rancho com um soldado do exército villista.

Vivendo Tita e Pedro sobre o mesmo teto, se torna perceptível para Elena que ainda existe amor entre os dois, por isso, considera melhor separá-los; no entanto, a essa altura da narrativa, Rosaura já ganhou seu primeiro filho, Roberto. Tita ajuda o sobrinho a vir ao mundo e o amamenta em segredo, estabelecendo assim, uma relação maternal intensa com o filho da irmã e de Pedro. Contudo, Mamãe Elena segue firme em seu intento e manda-os embora. Longe do seu sobrinho, Tita não ve mais prazer em cozinhar, em cumprir suas tarefas e até mesmo em obedecer a sua mãe.

Com o desequilíbrio causado pela ausência do sobrinho na vida de Tita, presenciamos o momento clímax da narrativa e também da vida da protagonista, tendo em vista que ela "sentiu o teto cair-lhe sobre a cabeça" (ESQUIVEL, 2006, p. 82) ao ser noticiada de que por falta de comida, seu sobrinho morreu. Em estado de choque e inconformidade, Tita se revolta com a mãe a ponto de lhe dizer que a culpa pela morte de Roberto é dela e acrescenta: "[...] olhe o que faço com suas ordens! Já me cansei! Cansei de lhe obedecer” (ESQUIVEL, 2006, p. 82).

Para Mamãe Elena, esta atitude afrontosa de Tita não passa de loucura, por isso, pede ao médico da família que a interne em um hospício. A ida para o hospital de loucos configuraria a primeira saída da protagonista do ambiente em que vivera desde o nascimento e, consequentemente, tal experiência seria difícil, especialmente porque ficaria longe da cozinha. No entanto, o médico decide não a levar para o hospício, mas para sua casa a fim de poder acompanhá-la de perto. Esta fase da vida de Tita é de amadurecimento, autodescoberta, libertação, pois "ao lado da mãe, o que suas mãos tinham de fazer estava friamente determinado" e agora "ao vê-las livres [...] não sabia o que pedir-lhes que fizessem, nunca havia decidido por si mesma” (ESQUIVEL, 2006, p.88-89). Nesse sentido, Dr. John torna-se peça fundamental para o desenvolvimento da protagonista.

O período vivido por Tita na casa do doutor é determinante para a libertação do medo e da repressão provocados por Mamãe Elena. Ao voltar para o rancho para cuidar de sua mãe, que se encontra paraplégica, pela primeira vez consegue sustentar o olhar nela. Simbolicamente, o olhar "é carregado de todas as paixões da alma e dotado de um poder mágico, que lhe confere uma terrível eficácia. $\mathrm{O}$ olhar é o instrumento das ordens interiores: ele mata, fascina, fulmina, seduz, 
assim como exprime" (CHEVALIER, 1994, p. 652). Do mesmo modo, Tita carrega esse olhar diferente, que transpassa e exprime a ideia de força, para poder romper com qualquer regra e enfrentar o que foi para ela o mais terrível dos olhares.

Tita volta para a cozinha do rancho com outra expectativa e disposta a não se submeter aos mandos nem desejos de sua mãe, uma vez que já passou a conhecer o prazer de tomar suas próprias decisões.

Pouco depois do regresso de Tita, Mamãe Elena morre. A princípio, a causa da morte não é descoberta, mas, após o quarto ser vistoriado, é encontrado um vomitório extremamente forte a ponto de provocar a morte. Sendo assim, Mamãe Elena, confiante de que Tita, no propósito de se ver livre da tradição e então casarse, a envenenaria através da sua alimentação, decidiu cometer o suicídio. "Durante o enterro realmente chorou pela mãe. Mas não pela mulher castradora, que a havia reprimido toda a vida, mas sim por esse ser que havia vivido um amor frustrado" (ESQUIVEL, 2006, p. 114).

Tita agora se vê independente das imposições da mãe e livre para amar e casar-se "e jurou diante de seu túmulo que nunca renunciaria ao amor, acontecesse o que acontecesse" (ESQUIVEL, 2006, p. 114). Entretanto, sua felicidade mais uma vez se converte em aborrecimento, já que Rosaura decreta que sua filha, Esperanza, que nasceu após a morte de seu primeiro filho, não poderia se casar, uma vez que deverá cuidar dela até a morte. Tal atitude é inaceitável para Tita, que vê na obrigação de impedir que a irmã perpetue essa "tradição por demais desumana” (ESQUIVEL, 2006, p. 124). Desta forma, a protagonista trava uma luta com a irmã, pois não quer permitir que sua sobrinha venha a viver como ela.

Michel Butor estabelece o conceito de espaço ficcional e afirma que "toda ficção se inscreve [...] em nosso espaço [este] é capaz de exprimir metaforicamente essa distância entre o lugar da leitura e aquele ao qual nos leva a narrativa” (BUTOR, 1974, p. 42). Para que o leitor consiga adentrar a este espaço é preciso que o cenário seja indicado e assim, o domínio da leitura pode ser alcançado, como propõe o autor propõe.

O romance tem como cenário a revolução Mexicana e uma sociedade patriarcal, em que o único lugar onde a mulher poderia ter voz e reconhecimento é dentro do seu mundo marginalizado. A cozinha sempre pertenceu ao universo feminino, considerado como um espaço de confinamento. Para Tina Escaja, “El 
nuevo centro que plantea la novela de Laura Esquivel es el del universo tradicional de la mujer considerado hasta entonces secundario y marginal. Y el polo espacial fundamental en el que se desenvuelve [...] la cocina" (ESCAJA, 2000, p. $571)$.

Em linhas gerais, a narrativa desenvolve-se por completo em torno da cozinha, espaço no qual "a personagem Tita nasce, descobre o seu amor e chora a sua perda; verbaliza a traição de sua mãe e de sua irmã mais velha e, enfim, se rebela. E neste espaço se concentra toda sua vida. É onde a vida acontece" (SANTOS, 1999, p. 124-5).

A história não é contada pela protagonista, mas sim por sua sobrinha-neta, herdeira do livro de cozinha, que "narra em cada receita esta história de amor enterrada” (ESQUIVEL, 2006, p. 204). Este é um dado que por vezes passa despercebido aos olhos do leitor, mesmo sendo exposto no início do romance: "mamãe dizia que era porque eu era tão sensível à cebola quanto Tita, minha tia-avó" (ESQUIVEL, 2006, p. 4). Esta sobrinha-neta é a quarta geração da família de La Garza, "é o fio condutor da história, é o personagem que precisa conhecer o passado de sua tia-avó para compreender a situação feminina atual no país em que vive" (SANTOS, 1999, p. 125).

De acordo com Miranda (2013, p. 95), a construção da protagonista "se dá [...] em dois elementos [...] o amor e a cozinha”. Ou seja, o foco desta narrativa não se concentra somente no amor entre Tita e Pedro, mas especialmente na crítica da ideologia patriarcal imposta.

Dentro da cozinha, Tita altera os sabores dos alimentos e cria, portanto, um espaço próprio, subvertendo o lugar que sempre foi considerado de repreensão, confinamento e marginalização em um espaço de comunicação com o mundo. É através do livro que novas gerações terão o contato com o momento de "mudança, aquisição de cidadania, voz e rosto pelas mulheres” (SANTOS, 1999, p. 125).

Tita não luta somente por benefícios próprios, está empenhada em romper com a tradição que oprime todas as mulheres ao seu redor. Deste modo, convertese em uma heroína que age através da cozinha para que a sociedade venha reconhecer seu valor e possa ser ouvida, tanto que expressa sua inconformidade perante a intenção de ter sua sobrinha submetida a uma tradição estúpida. 
Esperanza, a sobrinha fadada aos mesmos infortúnios da protagonista, carrega em seu nome o significado que explicita e simboliza esse momento de superação da tradição e, por isso é capaz de conquistar seu espaço enquanto mulher, enquanto sujeito.

\section{CONCLUSÃO}

A cozinha - ambiente há muito tempo considerado de confinamento e de reclusão - converte-se em um lugar de destaque, ao ser transformado em um espaço de emissão da voz da mulher. A cozinha está estreitamente ligada à construção e à evolução da protagonista, pois é o lugar onde ocorrem todos os ciclos de sua vida. É a partir desse espaço que Tita empreende sua luta pelo rompimento da tradição familiar castradora e pela quebra do silêncio imposto pela sociedade patriarcal.

A atuação da protagonista dentro da cozinha é muito significativa, pois ela a transforma em seu próprio mundo e por isso age de forma inusitada, desde seu nascimento sobre a mesa da cozinha, até a subversão que há em alterar o comportamento dos convidados com os pratos ali preparados; dessa maneira, Tita cria um novo código de comunicação que a levará, como mulher, a conquistar o espaço negado a todas as outras na sociedade.

A forma como Tita atua nesse espaço está metaforicamente associada ao movimento de luta que a mulher enfrenta mediante a sociedade patriarcal. De acordo com Santos (1999, p. 126), “ser mulher não poderá ser nunca um empecilho para a concretização de seus objetivos”, o que mais uma vez ressalta que na vida em sociedade os direitos e deveres devem ser iguais para todos, de modo que a voz da mulher necessita ter o mesmo espaço e peso que a do homem em todas as esferas e decisões.

Tal ideia também pode ser ampliada no tocante ao âmbito do cânone literário, já que, em pleno século XXI, é possível observar julgamentos misóginos. Sendo assim, o estudo da crítica feminista pode ser um respaldo para a alteração de percepções em relação a conceitos do mundo atual.

\section{REFERÊNCIAS}

BUTOR, Michel. O espaço no romance. In: Repertório. São Paulo: Perspectiva, 1974. p. 39-47. 
CHEVALIER, Jean; GHEERBRANT, Alain. Dicionário de símbolos: mitos, sonhos, costumes, gestos, formas, figuras, cores, números. André Barbault et al. (Col.). Carlos Sussekind (Coord.). Trad. Vera da Costa e Silva. 21. ed. Rio de Janeiro: José Olympio, 2007.

ESCAJA, Tina. Reinscribiendo a Penélope: mujer e identidad mejicana en Como agua para chocolate. Revista Iberoamericana. v. 66, n. 192, p. 571-86, jul./sep. 2000.

ESQUIVEL, Laura. Como agua para chocolate. Buenos Aires: Debolsillo, 2009.

ESQUIVEL, Laura. Como água para chocolate. Trad. Olga Savary. São Paulo: Martins Fontes, 2006.

MIRANDA, Kátia Rodrigues Mello. A pedra e a água: uma leitura comparada de Pedro Páramo (1955), de Juan Rulfo, e Como água para chocolate (1989), de Laura Esquivel. Tese de Doutorado em Letras, Faculdade de Ciências e Letras, Universidade Estadual Paulista Júlio de Mesquita Filho. Assis, 2013.

SACRAMENTO, Adriana Rodrigues. A culinária de sentidos: corpo e memória na literatura contemporânea. Tese de Doutorado em Literatura. Universidade de Brasília, Brasília, 2009. Disponível em: <http://repositorio.unb.br/handle/10482/4926>. Acesso em: 26 ago. 2016.

SANTOS, Ana Cristina dos. Algumas reflexões sobre a voz feminina na moderna narrativa hispano-americana. In: Anuario Brasileño de Estudios Hispánicos, $n^{\circ}$ 9, 1999, p. 117-128. Disponível em <www.educacion.gob.es/exterior/br/es/publicaciones/anuario/abeh99.pdf>. Acesso em: 5 de maio de 2015.

SHOWALTER, Elaine. A crítica feminista no território selvagem. In: HOLLANDA, Heloisa Buarque de (Org.). Tendências e impasses: o feminismo como crítica da literatura. Rio de Janeiro: Rocco, 1994. pp. 23-57.

ZOLIN, Lúcia Osana. Literatura de autoria feminina. In: BONNICI, Thomas; ZOLIN, Lúcia Osana (Org.). Teoria literária: abordagens históricas e tendências contemporâneas. 2. ed. Maringá: Eduem, 2005. pp. 275-83. 